\title{
The Effect of Fenugreek on the Gene Expression of Arachidonic Acid Metabolising Enzymes
}

\begin{tabular}{|r|l|}
\hline Journal: & Phytotherapy Research \\
\hline Manuscript ID: & PTR-09-0106.R1 \\
\hline Wiley - Manuscript type: & Full Paper \\
\hline Autho Submitted by the & 22-Apr-2010 \\
\hline Complete List of Authors: & $\begin{array}{l}\text { Varjas, Timea; University of Pécs, Faculty of Medicine, Institut of } \\
\text { Public Health } \\
\text { Nowrasteh, Ghodratollah; University of Pécs, Faculty of Medicine, } \\
\text { Institute of Public Health } \\
\text { Budán, Ferenc; University of Pécs, Faculty of Medicine, Institute of } \\
\text { Public Health } \\
\text { Horváth, Gábor; University of Pecs, Faculty of Medicine, Institute of } \\
\text { Public Health } \\
\text { Cseh, József; Szent György Country Hospital, Department of } \\
\text { Oncology } \\
\text { Gyöngyi, Zoltán; University of Pécs, Faculty of Medicine, Institute of } \\
\text { Public Health } \\
\text { Makai, Sándor; University of West Hungary Agriculture Science } \\
\text { Faculty, Department of Medicinal and Aromatic Plants } \\
\text { Ember, István; University of Pecs, Faculty of Medicine, Institute of } \\
\text { Public Health }\end{array}$ \\
\hline \hline Keyword: & $\begin{array}{l}\text { Fenugreek, gene expression, chemoprevention, lipoxygenase, } \\
\text { cyclooxygenase }\end{array}$ \\
\hline \hline
\end{tabular}

\section{s.) ScholarONE \\ Manuscript Central}




\section{Abstract}

The main bioactive compounds of Trigonella foenum graecum L. (fenugreek) seeds are protodioscin, trigoneoside, diosgenin, yamogenin, which have anti-carcinogenic potency through inhibition of cell proliferation and inhibition of prostaglandin synthesis.

We examined the effect of fenugreek on $A L O X$ and $C O X$ genes in $\mathrm{AKR} / \mathrm{J} \mathrm{H}-2^{\mathrm{k}}$ mice exposed to dimethylbenz $[\alpha]$ anthracene (DMBA), the potent carcinogen. Expression pattern of these genes was determined by detecting the mRNA expression in various tissues (the lungs, liver, spleen and the kidneys) in four groups of mice. Two groups were fed with normal and two of them with fenugreek containing nutriment. Each group divided into DMBA treated and control groups. Mice were autopsied on the $7^{\text {th }}$ day after DMBA treatment for mRNA isolation. Fenugreek consumption itself did not change gene expression compared to the control group. DMBA could increase expression of ALOX12, ALOX15, ALOX5 genes mainly in all organs. Fenugreek consumption was generally protective in each organ in different manner. DMBA treatment increased COX2 gene expression, but fenugreek were protective in all tissues examined. In COX1 gene, fenugreek diet could suppress the expression, except for spleen, independently from carcinogen exposure. Therefore via inhibiting the arachidonic acid metabolism fenugreek may prevent tumorigenesis.
\end{abstract}




\section{Introduction}

Fenugreek (Trigonella foenum graecum L.) seed (semen), popularly known as „Methi” is available in most Asian countries especially in India and it is used as one of the most common spices (Sur et al., 2001).

The seeds and leaves (folium) of fenugreek are edible and are used as condiments and as ayurvedic medicine in treatment of diabetes, hypercholesterolemia, wound healing, inflammation, and gastrointestinal diseases (Raju et al., 2004). Bioactive compounds of fenugreek seed modulate the expression of several enzymes, especially those which involved in glucose and lipid metabolism. Fenugreek seed consists of $75 \%$ seed coat (testa) and $25 \%$ protein (albumen). The seed coat functions as spice and contains essential oils (17 kinds) that give the specific fragrance, saponins, steroidal saponins like diosgenin, yamogenin and proteins. Fenugreek seed coat contains 10-15\% of saponin and approximate $32 \%$ of crude protein. On the other hand, albumen consists of $80 \%$ water soluble substances (e.g. viscous polysaccharide and viscous polymer) and $20 \%$ water insoluble substances (e.g. alkaloides) (Table 1.) (Noor, 2008). The main bioactive compounds isolated from fenugreek seeds are protodioscin, trigoneoside, diosgenin, yamogenin (Raju et al., 2004).

Generally speaking, few researches have been carried out on the effect of this herb on cancer. Extracts of fenugreek seeds have been found to have anticarcinogenic potency in different settings, such as proven antineoplastic effect in Ehrlich ascites carcinoma (EAC) model in Balb/C mice more than $70 \%$ inhibition of tumour cell growth with respect to the control were detected (Sur et al., 2001). Moreover in vitro experiments indicated that diosgenin inhibits cell growth and induces apoptosis in HT-29 human colon cancer cell line in a dose-dependent manner. Furthermore, diosgenin induced 
apoptosis in HT-29 cells at least in part by inhibition of bcl-2 and by induction of caspase-3 protein expression (Raju et al. 2004).

Certain phytochemical compounds, eg. flavonoids (flavans, flavanones, flavones, flavanonols, flavonols, catechins, anthocyanidins and isoflavone) are proven to exhibit antioxidant, anti-inflammatory, chemopreventive, antiviral and antibacterial, as well as a direct cytoprotective effect on coronary and vascular systems, the pancreas and the liver (Burnett et al., 2007; Amin et al, 2005; Devasagayam and Sainis, 2002). The cellsignalling pathways inhibited by curcumin alone include NFkB, AP-1, STAT3, Akt, Bcl2, BclX, caspases, PARP, IKK, EGFR, HER2, JNK, MAPK, COX2, and ALOX5 (Aggarwal and Shishodia, 2006). Diosgenin as a precursor of steroid hormones like progesterone and cortisone has an anti-inflammatory effect (Norton, 1998). Moreover Moalic et al. and Corbiere et al. reported that diosgenin inhibits cell proliferation in the human osteosarcoma 1547 cell line by the induction of apoptosis by cell cycle arrest in G1 phase as well principally by increasing the expression of the tumour suppressor TP53 (Moalic et al., 2001; Corbiere et al., 2003 ). Other authors have described that diosgenin suppressed the TNF-induced NFkB activation as determined by DNA binding, activation of $\mathrm{I} \kappa \mathrm{B} \alpha$ kinase, I $\mathrm{I} \mathrm{B} \alpha$ phosphorylation, I $\mathrm{I} \mathrm{B} \alpha$ degradation, p65 phosphorylation, and p65 nuclear translocation through the inhibition of Akt activation. NF- $\kappa$ B-dependent reporter gene expression was also abrogated by diosgenin. Diosgenin suppresses proliferation, inhibits invasion, and suppresses osteoclastogenesis through inhibition of NF- $\mathrm{BB}$-regulated gene expression and enhances apoptosis induced by cytokines and chemotherapeutic agents (Shishodia and Aggarwal, 2005). On the basis of these data listed above, diosgenin and other fenugreek seed constituents possess anticarcinogenic properties, suggesting their potential as appropriate phytochemicals for cancer prevention. It is known that steps of carcinogenesis can be influenced by many compounds of plant origin (Raju et al., 2004). More publications have dealt with the 
complex inhibitory effects of rezveratol, curcumin, quercetin on tumour formation induction of suppressor genes and apoptosis (Lin, 2007; Burnett et al., 2007). Moreover in animal experiment Bhatia et al. highlighted the possible protective effect of fenugreek in cyclophosphamide treatment, which causes toxicity by its reactive metabolites such as acrolein and phosphoramide mustard. Fenugreek is known for its hypoglycemic, anti-inflammatory and immunomodulatory activity, promising protective medicinal herb for consideration in complementary therapy for cancer patients under chemotherapeutic interventions (Bhatia et al., 2006).

The COXs and ALOXs are two important enzyme classes that metabolize polyunsaturated fatty acids and affect carcinogenesis. The ALOXs convert arachidonic acid and linoleic acid and other polyunsaturated fatty acids into biologically active metabolites, those influence cell signalling, structure, and metabolism (Shureiqi and Lippman, 2001). According to the literature, prostate, the lungs, and other cancer cell lines express ALOX5, resulting the formation of a variety of metabolically active products with different roles in carcinogenesis (Burnett et al., 2007). Both of COX1 and COX2 isoforms are responsible for the synthesis of prostaglandin $\mathrm{E}_{2}\left(\mathrm{PGE}_{2}\right)$, and there is evidence for correlation between increased level of $\mathrm{PGE}_{2}$ and carcinogenesis presented (Janakiram and Rao, 2008).

In summary the biologically active compounds of fenugreek may be tools of chemopreventive strategies as well, such as the possible inhibition of prostaglandin of metabolic pathway with lipoxygenase (ALOX) and cyclooxygenase (COX) enzymes.

Li et al. examined ALOX5 expression in DMBA-induced hamster and human oral cancer tissues by immuno histochemistry. In addition, COX2 expression was investigated in hamster oral tissues using in situ hybridization, as well. Evidence were presented for the chemopreventive effects of a specific ALOX5 inhibitor (Zileuton) and a specific COX2 inhibitor (celecoxib), either alone or in combination on the DMBA- 
induced hamster model at the post-initiation stage through topical application (Li et al., 2005).

In the literature the effect of fenugreek seed extract on the expression of ALOXs and COXs genes is not reported yet. Nor the effect of DMBA exposure on the expression of ALOXs and COXs genes were examined yet. Therefore the chemopreventive effects of fenugreek by influencing the expression of genes involved in fatty acid metabolism (ALOXs and COXs) in AKR/J H-2 ${ }^{\mathrm{k}}$ inbred mice animal model exposed to carcinogenic dimethylbenz $[\alpha]$ antracene (DMBA) was examined in this study. 


\section{Material and Methods}

Animals: In this experiment six mice (6 week female AKR/J H-2 ${ }^{\mathrm{k}}$ inbred) were used in each group. (The mice were bred in the animal test laboratory of the University of Pécs, Faculty of Medicine, Institute of Public Health).

Special feed preparation: Special food preparation. Special food was prepared as follows: the ground form of normal pet food granules were made, then the same quantity (50\% mass) of ginseng dried fenugreek seed power power (obtained from University of West Hungary, Agriculture Science Faculty, Department of Medicinal and Aromatic Plants) was mixed in. By adding a small quantity of water, rod-shape objects were formed and dried at room temperature.

The treatment of the AKR/J H-2 ${ }^{\mathrm{k}}$ mice. The first group of mice was fed with normal nutriment; the second group was fed with the special nutriment for 7 days. A third group was fed with normal nutriment and DMBA was administered on day 6. The fourth group was fed with special nutriment, and similarly to the third group, DMBA was administered intraperitoneally (20 mg/bw kg doses DMBA) on day 6 (Table 2). (Perjési et al, 2000).

Isolation of mRNA. All the groups were autopsied on day 7, $24 \mathrm{~h}$ postcarcinogenic exposure, with subsequent isolation of mRNA from lung, liver, spleen and kidney, using MagNA Pure Compact Instrument (Roche Applied Science).

Quantitative RT-PCR. Quantitative RT-PCR was performed using the Gene Amp® 5700 Sequence Detection System (Applied Biosystems) according to the manufacturer's instructions. All the primers were designed by Primer Express ${ }^{\mathrm{TM}}$ Software (Applied Biosystems) and synthesized by Integrated DNA Technologies. Relative gene expression values were calculated by the comparative $\mathrm{C}_{\mathrm{T}}$ (threshold cycle) method ( $\Delta \Delta \mathrm{C}_{\mathrm{T}}$ method, Applied Biosystems). The comparative $\mathrm{C}_{\mathrm{T}}$ method gives the amount of 
target gene normalized to an endogenous reference gene and to a relative calibrator sample. Primers for the genes and endogenous reference gene are listed in Table 3.

Statistical anatysis. Mean values and ranges were derived from quantitative results of mRNA gene expression measurement of three independent parallel experiments. Qualitative variables were summarized by means of absolute frequencies and percentages. For all calculations, $X^{2}$ tests were performed, where the level of significance was set at $5 \%(95 \% \mathrm{Cl}$ - confidence interval).

License: All legal licenses needed to perform this study were in our possession. 


\section{Results}

The mRNA expressional profiles of enzymes playing part in arachidonic acid metabolism and prostaglandin synthesis are demonstrated in Figures 1-5.

Figure 1. represents the gene expression pattern of arachidonate-12-lipoxygenase in liver, lung, spleen and kidney tissues. The gene expression did not change in the tissues of mice on fenugreek diet compared to the mice being on normal diet in the control group. However, the expression of $A L O X 12$ mRNA increased in the liver, the lungs and spleen of the mice consuming fenugreek and exposed to DMBA. On the other hand, the DMBA increased the gene expression in the kidney tissue, but were suppressed by the fenugreek diet to the normal level.

The ALOX15 (arachidonate-omega-6-lipoxygenase) gene expression was increased by carcinogen exposure in all examined organs. Normal mRNA concentrations were found in the liver, the lungs and the kidneys of mice consuming fenugreek and exposed to DMBA. In the kidneys, fenugreek consumption decreased ALOX15 enzyme expression compared to the control group in untreated groups (Figure 2.).

Figure 3. demonstrates the expression pattern of the key gene of arachidonic acid metabolism (ALOX5; arachidonate-5-lipoxigenase). Isolated mRNA from examined organs revealed that the carcinogen have increased examined gene expression by $2.5-4$ folds. However, the carcinogen-caused elevated gene expression was inhibited by fenugreek consumption only in the liver and the kidneys.

Increased $C O X 1$ gene expression in response to DMBA exposure was noticed in all of the organs, except for spleen (Figure 4.).

Fenugreek diet suppressed COX2 (cyclooxygenase 2 or prostaglandin-endoperoxidase syntase-2) gene expression independently from carcinogen exposure in the organs of mice. The increased expression of COX2 in response to DMBA treatment was suppressed by fenugreek diet in all of the four examined organs (Figure 5). 


\section{Discussion}

Chemoprevention strategies can benefit from observations linked to the identification of intermediate/surrogate biomarkers giving evidence for usefulness of various nutrients/drugs with specific cancer related molecular targets. As the early stages of tumour promotion and progression rate limiting, successful chemopreventive targeting of early molecular events inhibiting carcinogenesis or enhancing tumour suppression can have high impact on outcomes.

In recent years, genetic information about cancer, molecular signalling and metabolic pathways has permitted to target therapies and detecting specific molecules for prevencion (Janakiram and Rao, 2008). The arachidonic acid pathways are possible targets of prevention. Lipoxygenases leads to the formation of a variety of metabolically activated products from linolenic and arachidonic acids which have different roles in carcinogenesis (Burnett et al., 2007).

Arachidonic acid is converted by ALOX5 to 5(S)-HETE (5(S)-Hydroxyeicosatetraenoic Acid), which in turn is converted to $\mathrm{LTA}_{4}$ (Leukotriene $\mathrm{A}_{4}$ ) and then to $\mathrm{LTB}_{4}$ (Leukotriene $\mathrm{B}_{4}$ ) by $\mathrm{LTA}_{4}$ hydrolase (Shureiqi and Lippman, 2001). Several studies have suggested a link between 5(S)-HETE formation and carcinogenesis in prostate and the lungs as well derived cancer cell lines expressing ALOX5 and FLAP mRNA (Shureiqi and Lippman, 2001; Anderson et al, 1998). ALOX5 overexpression recently has been documented in human prostate cancer tissue (Gupta et al, 2001), and 5(S)HETE formation and inhibition the growth of prostate cancer cells has been detected as well (Ghosh and Myers, 1997). Several lines of evidence indicate that the ALOX12 product 12(S)-HETE (12(S)-hydroxyeicosatetraenoic acid) contributes substantially to carcinogenesis (Tang and Honn, 1999). The expressions of ALOX12 mRNA and encoded protein have been detected in prostate, melanoma, and some other cancer cell lines (Shureiqi and Lippman, 2001, Timar et al., 2000). ALOX12 in tumour cells 
produces 12(S)-HETE, and 12(S)-HETE promotes invasion and metastasis (Shureiqi and Lippman, 2001).

Arachidonate-15-lipoxygenase-1 and Arachidonate-15-lipoxygenase-2 are two isoenzymes of ALOX15 that appear to exert important anticarcinogenic effects through the metabolism of polyunsaturated fatty acids. The preferred substrate for Arachidonate15-lipoxygenase-1 is linolenic acid and for Arachidonate-15-lipoxygenase-2 is arachidonic acid (Shureiqi and Lippman, 2001). The main oxidative metabolite of linolenic acid in human cells is 13(S)-HODE (13(S)-hydroxyoctadecadienoic acid) (Shureiqi and Lippman, 2001). Studies have suggested that 13(S)-HODE enhances cell proliferation, potentially the mitogenic response to EGF in fibroblasts and in Syrian hamster embryo cells, and breast cancer cells (Shureiqi and Lippman, 2001; Glasgow et al., 1992). The transfection of C-erbB-2 (a protooncogene similar to EGF receptor) into normal fibroblasts increases 13(S)-HODE production. The activity level of 13(S)HODE dehydrogenase, which metabolizes 13(S)-HODE to 13-oxo-octadecadienoic acid, decreases the malignant transformation of colonic epithelial cells undergo (Shureiqi and Lippman, 2001). These data assume that overexpression of ALOX enzymes could enhance oncogenesis and through the ability of suppressing them could be chemopreventive.

Cyclooxygenase-1 and Cyclooxygenase-2 (COX1 and COX2) are the two isoforms of the COX enzyme (Janakiram and Rao 2008; Brink et al., 2004). COX1 and COX2 catalyze the conversion of arachidonic acid to eicosanoids, (like prostaglandins and thromboxanes) via formation of endoperoxides. The COX1 isoform synthesizes prostaglandins that are required for normal physiologic function like gastrointestinal cytoprotection and platelet activity. COX2 is not detectable in most of the normal tissues; however, it is induced at sites of inflammation by cytokines, growth factors, tumour promoters and other agents. Both isoforms are also responsible for the synthesis 
of prostaglandin $\mathrm{E}_{2}\left(\mathrm{PGE}_{2}\right)$, and there are evidences for correlation between increased level of $\mathrm{PGE}_{2}$ and tumorigenesis (Janakiram and Rao, 2008; O'Neill and FordHutchinson; 1993, Bengmark, 2006). Regarding the biological effect, its enzyme modulating ability has been detected by the expression of enzymes involved in lipid metabolism. Moreover, the results of this experiments suggests that bioactive components (protodioscin, trigoneoside, diosgenin, yamogenin) of fenugreek have tumour-preventive and anticarcinogenic effect (Raju et al., 2004; Hibasami et al, 2003; Sur et al., 2001).

In our experiments the increased expression of ALOX12 mRNA in response to DMBA was suppressed by fenugreek containing nutriment only in the kidneys. Increased level of expression of ALOX15 gene was detected in all of the four examined tissues after DMBA treatment. Normal levels of mRNA concentrations were detected in the liver, lung and kidney tissues of mice kept on fenugreek containing diet. Similar results were found for the key enzyme of arachidonic metabolism (ALOX5). The expressions of the genes hich play role in prostaglandin biosynthesis (COX1, COX2) were down regulated as a result of fenugreek containing nutriment.

Comparing our results to other studies on different cell lines, it seems that the biologically active components of fenugreek are able to exert their chemopreventive effects via inhibiting the arachidonic acid metabolism. Studying the molecular targets of the herbs used for hundreds of years in eastern medicine is one of the important tasks of the modern medico-biological researches in the recent days. Fenugreek with its high saponin content (in admission to its pleasant taste) can be a supplementary factor in our strategy for preventing tumorigenesis. Moreover fenugreek seed extract has decreased the expression of genes taking part in inflammatory processes (eg. in the kidneys ALOX15 in comparison to the control group) considering its healing effect in ayurvedic medicine (for treatment of diabetes, hypercholesterolemia, wound healing, 
inflammation, and gastrointestinal diseases) (Raju et al., 2004). On the other hand chronic inflammatory processes elevate the risk of malignant transformation through increased cell necrosis, cytokine activity consequent stimulation of proliferation supporting regenerative processes. According to our results and data found in the literature, fenugreek seed and its biologically active compounds could have chemopreventive effect due to the suppression of ALOX and COX genes. 


\section{References}

Aggarwal BB and Shishodia S. 2006. Molecular targets of dietary agents for prevention and therapy of cancer. Biochem Pharmacol 71(10): 1397-1421.

Amin A, Alkaabi A, Al-Falasi S, Daoud SA. 2005. Chemopreventive activities of Trigonella foenum graecum (Fenugreek) against breast cancer. Cell Biol Int 29(8): 687-694

Anderson KM, Seed T, Vos M, Mulshine J, Meng J, Alrefai W, Ou D, Harris J. 1998. E. 5-Lipoxygenase inhibitors reduce PC-3 cell proliferation and initiate nonnecrotic cell death. Prostate 37: 161-173

Bengmark S. 2006. Curcumin, an atoxic antioxidant and natural NFKB, cyclooxygenase-2, lipooxygenase, and inducible nitric oxide synthase inhibitor: a shield against acute and chronic diseases. J Parenter Enteral Nutr 30(1): 45-51.

Bhatia K, Kaur M, Atif F, Ali M, Rehman H, Rahman S, Raisuddin S. 2006. Aqueous extract of Trigonella foenum-graecum L. ameliorates additive urotoxicity of buthionine sulfoximine and cyclophosphamide in mice. Food Chem Toxicol 44(10): 1744-1750.

Brink C, Dahlén SE, Drazen J, Evans JF, Hay DW, Rovati GE, Serhan CN, Shimizu T, Yokomizo T. 2004. International Union of Pharmacology XLIV. Nomenclature for the Oxoeicosanoid Receptor. Pharmacol Rev 56(1): 149-157

Burnett BP, Jia Q, Zhao Y, Levy RM. 2007. A medicinal extract of Scutellaria baicalensis and Acacia catechu acts as a dual inhibitor of cyclooxygenase and 5lipoxygenase to reduce inflammation. J Med Food 10(3): 442-51.

Corbiere C, Liagre B, Bianchi A, Bordji K, Dauça M, Netter P, Beneytout JL. 2003. Different contribution of apoptosis to the antiproliferative effects of diosgenin and other plant steroids, hecogenin and tigogenin, on human 1547 osteosarcoma cells. Int J Oncol 22(4): 899-905.

Devasagayam TPA, Sainis KB. 2002. Immune system and antioxidants, especially those derived from Indian medicinal plants. Indian J Exp Biol 40: 639-55.

Ghosh J, and Myers CE. 1997. Arachidonic acid stimulates prostate cancer cell growth: critical role of 5-lipoxygenase. Biochem. Biophys. Res Commun 235: 418423

Glasgow WC, Afshari CA, Barrett JC, Eling TE. 1992.Modulation of the epidermal growth factor mitogenic response by metabolites of linoleic and arachidonic acid in Syrian hamster embryo fibroblasts. Differential effects in tumor suppressor gene (+) and (-) phenotypes. J. Biol. Chem 267: 10771-10779

Gupta S, Srivastava M, Ahmad N, Sakamoto K, Bostwick DG, Mukhtar H. 2001. Lipoxygenase-5 is overexpressed in prostate adenocarcinoma. Cancer (Phila.) 91: 737-743

Hibasami H, Moteki H, Ishikawa K, Katsuzaki H, Imai K, Yoshioka K, Ishii Y, Komiya T. 2003. Protodioscin isolated from fenugreek (Trigonella foenum graecum 
L.) induces cell death and morphological change indicative of apoptosis in leukemic cell line H-60, but not in gastric cancer cell line KATO III. Int J Mol Med 11:23-6

Janakiram NB, Rao CV. 2008. Molecular markers and targets for colorectal cancer prevention. Acta Pharmacol Sin 29(1): 1-20

Li N, Sood S, Wang S, Fang M, Wang P, Sun Z, Yang CS, Chen X. 2005.

Overexpression of 5-lipoxygenase and cyclooxygenase 2 in hamster and human oral cancer and chemopreventive effects of zileuton and celecoxib. Clin Cancer Res 11(5): 2089-96.

Lin JK. 2007. Molecular targets of curcumin. Adv Exp Med Biol 595: 227-43.

Moalic S, Liagre B, Corbière C, Bianchi A, Dauça M, Bordji K, Beneytout JL. 2001. A plant steroid, diosgenin, induces apoptosis, cell cycle arrest and COX activity in osteosarcoma cells. FEBS Lett 506: $225-30$.

Noor EA. 2008. Comparative Study on the Corrosion Inhibition of Mild Steel by Aqueous Extract of Fenugreek Seeds and Leaves in Acidic Solutions. J Eng Applied Sci 3(1): 23-30

Norton SA. 1998. Useful plants of dermatology. III. Corticosteroids, strophanthus, and dioscorea. J Am Acad Dermatol 38: 256-9.

O'Neill GP, Ford-Hutchinson AW. 1993. Expression of RNA for cyclooxygenase-1 and cyclooxygenase-2 in human tissues. FEBS Lett 330: 156-60.

Perjési P, Gyöngyi Z, Bayer Z. 2000. Effect of E-2-(4'-methoxybenzylidene)-1benzosuberone on the 7,12-dimethylbenz[a] anthracene-induced onco/suppressor gene action in vivo II: A 48-hour experiment. Anticancer Res 20: 1839-48

Raju J, Patlolla JM, Swamy MV, Rao CV. 2004. Diosgenin, a Steroid Saponin of Trigonella foenum graecum (Fenugreek), Inhibits Azoxymethane-Induced Aberrant Crypt Foci Formation in F344 Rats and Induces Apoptosis in HT-29 Human Colon Cancer Cells. Cancer Epidemiol Biomarkers Prev 13(8): 1392-1398

Shishodia S and Aggarwal BB. 2006. Diosgenin inhibits osteoclastogenesis, invasion, and proliferation through the downregulation of Akt, I kappa B kinase activation and NF-kappa B-regulated gene expression. Oncogene 25(10):1463-73.

Shureiqi I, Lippman SM. 2001. Lipoxygenase Modulation to Reverse Carcinogenesis. Cancer Research 61: 6307-6312

Sur P, Das M, Gomes A, Vedasiromoni JR, Sahu NP, Banerjee S, Sharma RM, Ganguly DK. 2001. Trigonella foenum graecum (Fenugreek) Seed Extract as an Antineoplastic Agent. Phytother Res 15: 257-259

Tang K, and Honn KV. 1999. 12(S)-HETE in cancer metastasis. Adv Ex. Med Biol 447: $181-191$

Timar J, Raso E, Dome B, Li L, Grignon D, Nie D, Honn KV, Hagmann W. 2000. Expression, subcellular localization and putative function of platelettype 12lipoxygenase in human prostate cancer cell lines of different metastatic potential. Int. J. Cancer 87: 37-43 
1

2

3

4

5

10

Tables

Table 1. Fenugreek seed contains (Average yields \%)

\begin{tabular}{|c|c|c|}
\hline $40-45 \%$ & Polysaccharide & $\begin{array}{l}\text { Water-soluble polysaccharide } \\
\text { (galactmannane) } 18-20 \% \text { Hemi-cellulose } \\
\text { and cellulose } 22-25 \%\end{array}$ \\
\hline $27-30 \%$ & Proteins & $\begin{array}{l}\text { Isoleucine, 4-Hydroxyisoleucine, } \\
\text { Histidine, Leucine, Lysine, L-tryptophan, } \\
\text { Arginine }\end{array}$ \\
\hline $10-15 \%$ & $\begin{array}{l}\text { Saponins, Steroidal } \\
\text { sapinogens }\end{array}$ & $\begin{array}{l}\text { Graecunins, fenugrin B, fenugreekine, } \\
\text { trigofoenosides A-G Yamogenin, } \\
\text { diosgenin, smilagenin, sarsasapogenin, } \\
\text { tigogenin, neotigogenin, gitogenin, } \\
\text { neogitogenin, yuccagenin }\end{array}$ \\
\hline $6-10 \%$ & Oil & fenugreek oil \\
\hline \multirow[t]{2}{*}{$0.4 \%$} & Alkaloides & $\begin{array}{l}\text { Trimethylamine, Neurin, Trigonelline, } \\
\text { Choline, Gentianine, Carpaine and Betain }\end{array}$ \\
\hline & Other & Coumarin, lipids, vitamins, minerals \\
\hline
\end{tabular}

Table 2. The treatment of the AKR/J mice

\begin{tabular}{l|l|c|c} 
& \multicolumn{1}{|c|}{1 to $7^{\text {th }}$ day } & $6^{\text {th }}$ day & $7^{\text {th }}$ day \\
\hline Group 1 & normal nutriment & & \\
\hline Group 2 & special nutriment & & \\
\hline Group 3 & normal nutriment & autopsy \\
\hline Group 4 & special nutriment & DMBA i.p. &
\end{tabular}


Table 3. Listed the primers for the genes and endogenous reference gene

\begin{tabular}{|c|c|c|}
\hline Gene name & Symbol & Forward Primer / Reverse Primer \\
\hline $\begin{array}{l}\text { Prostaglandin-endoperoxidase } \\
\text { syntase } 1 \text { (cyclooxigenase } 1 \text { ) }\end{array}$ & COX1 & $\begin{array}{l}\text { 5' CCAGAACCAGGGTGTCTGTGT 3' } \\
5^{\prime} \text { GTAGCCCGTGCGAGTACAATC } 3^{\prime}\end{array}$ \\
\hline $\begin{array}{l}\text { Prostaglandin-endoperoxidase } \\
\text { syntase } 2 \text { (cyclooxigenase } 2\end{array}$ & $\mathrm{COX} 2$ & $\begin{array}{l}\text { 5' TGGTGCCTGGTCTGATGATG 3' } \\
\text { 5' GTGGTAACCGCTCAGGTGTTG 3' }\end{array}$ \\
\hline $\begin{array}{l}\text { Arachidonate omega-6- } \\
\text { lipoxygenase }\end{array}$ & ALOX15 & $\begin{array}{l}\text { 5'-GACCGAGGGTTTCCTGTCTC-3' } \\
\text { 5'-TGTCTCCAGCGTTGCATCC-3' }\end{array}$ \\
\hline Arachidonate 12-lipoxygenase & ALOX12 & $\begin{array}{l}\text { 5' TTTTATTTTTAAATGCCTAAACAAG 3' } \\
\text { 5' ACACTCCACATTAGTATTCTAACTACA } \\
\text { 3' }\end{array}$ \\
\hline Arachidonate 5-lipoxygenase & ALOX5 & 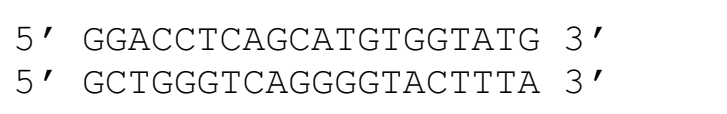 \\
\hline $\begin{array}{l}\text { Hypoxanthine guanine } \\
\text { phosphoribosyl transferase } 1\end{array}$ & HPRT1 & $\begin{array}{l}5^{\prime} \text { CAGGACTGAAAGACTTGCTC 3' } \\
5^{\prime} \text { TCATAGGAATGGACCTATCAC } 3^{\prime}\end{array}$ \\
\hline
\end{tabular}




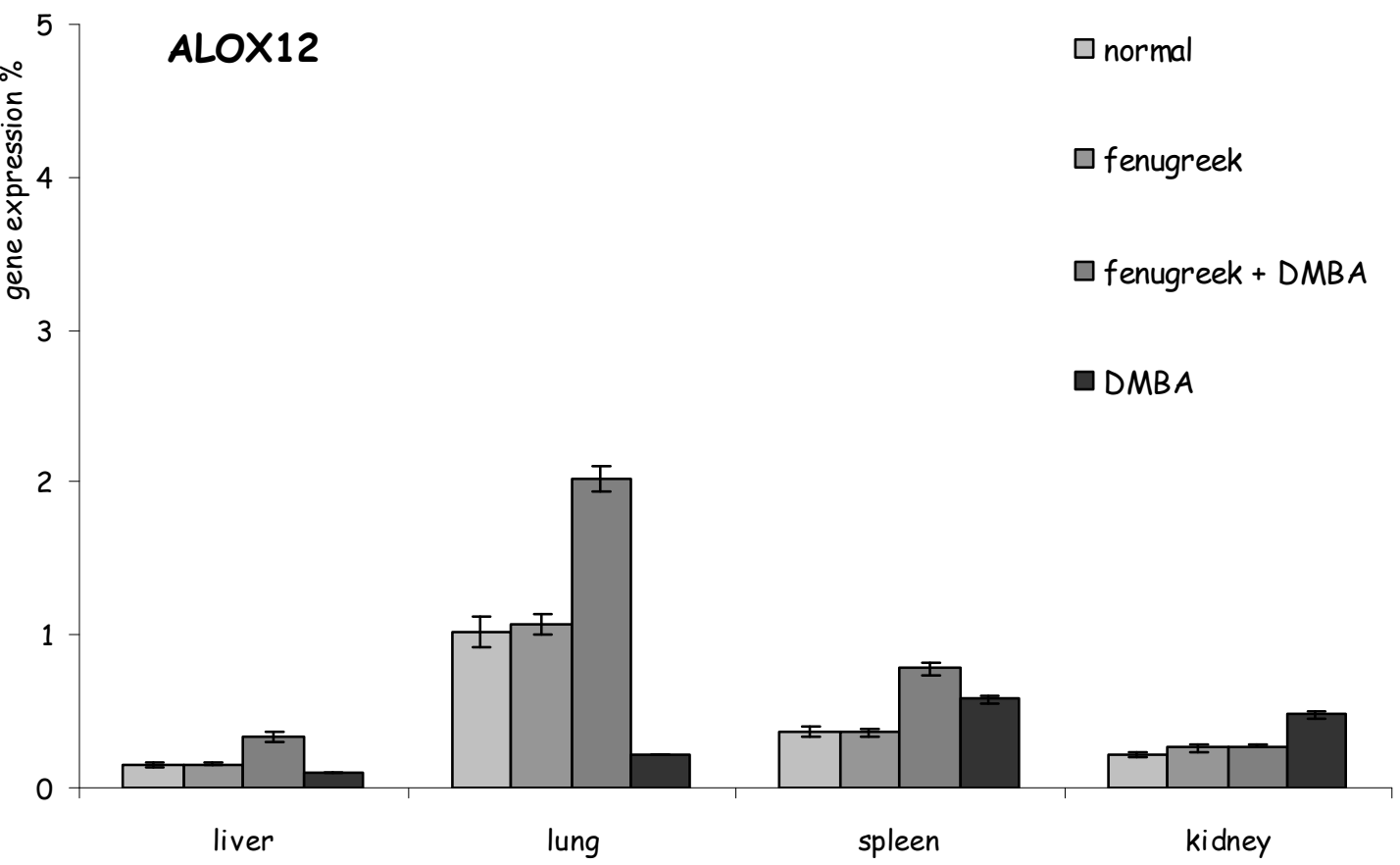

Figure 1.: The ALOX12 gene expression pattern and confidences interval of mRNA isolated from $\mathrm{AKR} / \mathrm{J}$ mice liver, lung, spleen and kidney tissues (the arbitrary unit is gene expression \% of HPRT1 gene) 


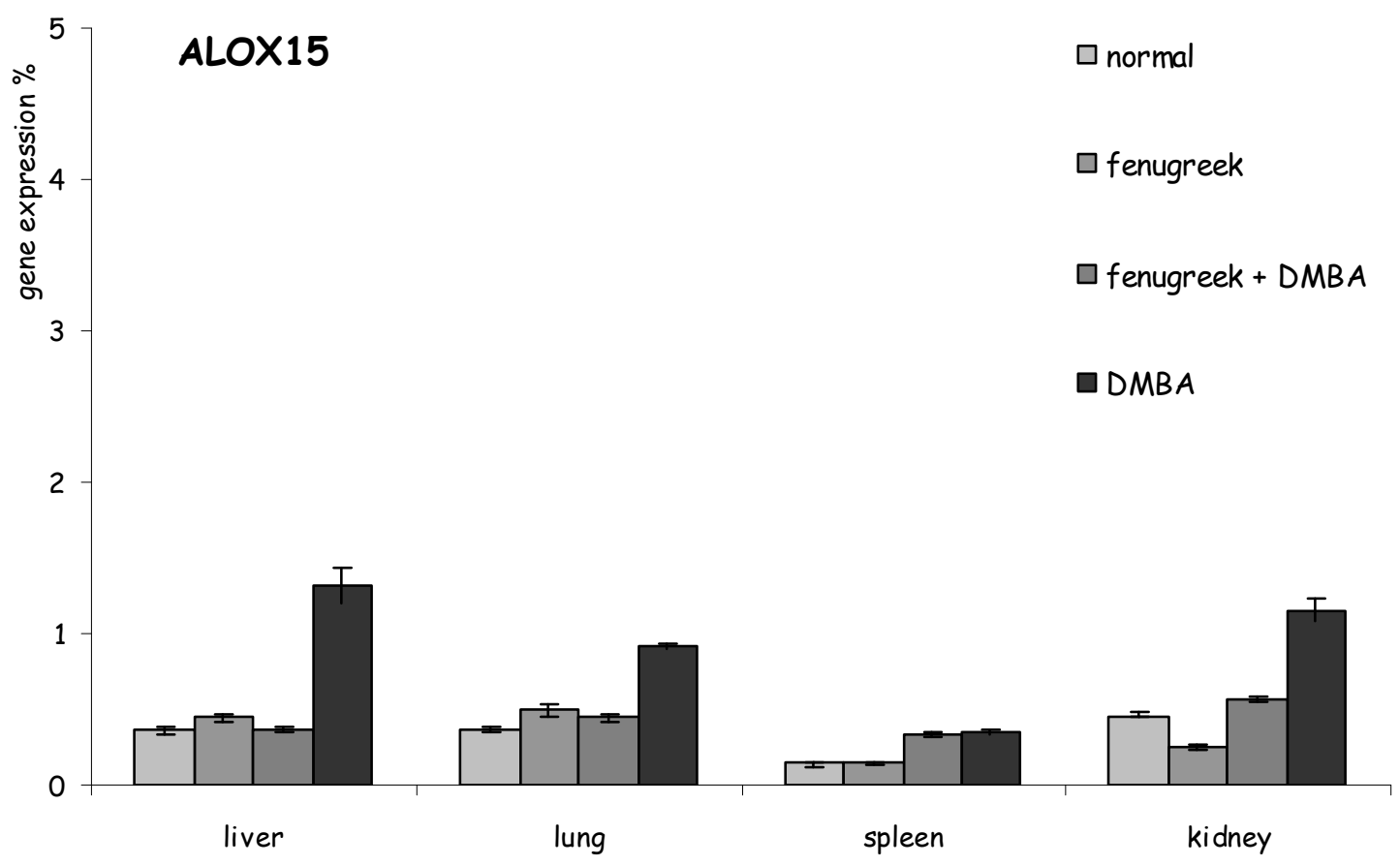

Figure 2.: The ALOX15 gene expression pattern and confidences interval of mRNA isolated from AKR/J mice liver, lung, spleen and kidney tissues (the arbitrary unit is gene expression $\%$ of HPRT1 gene) 


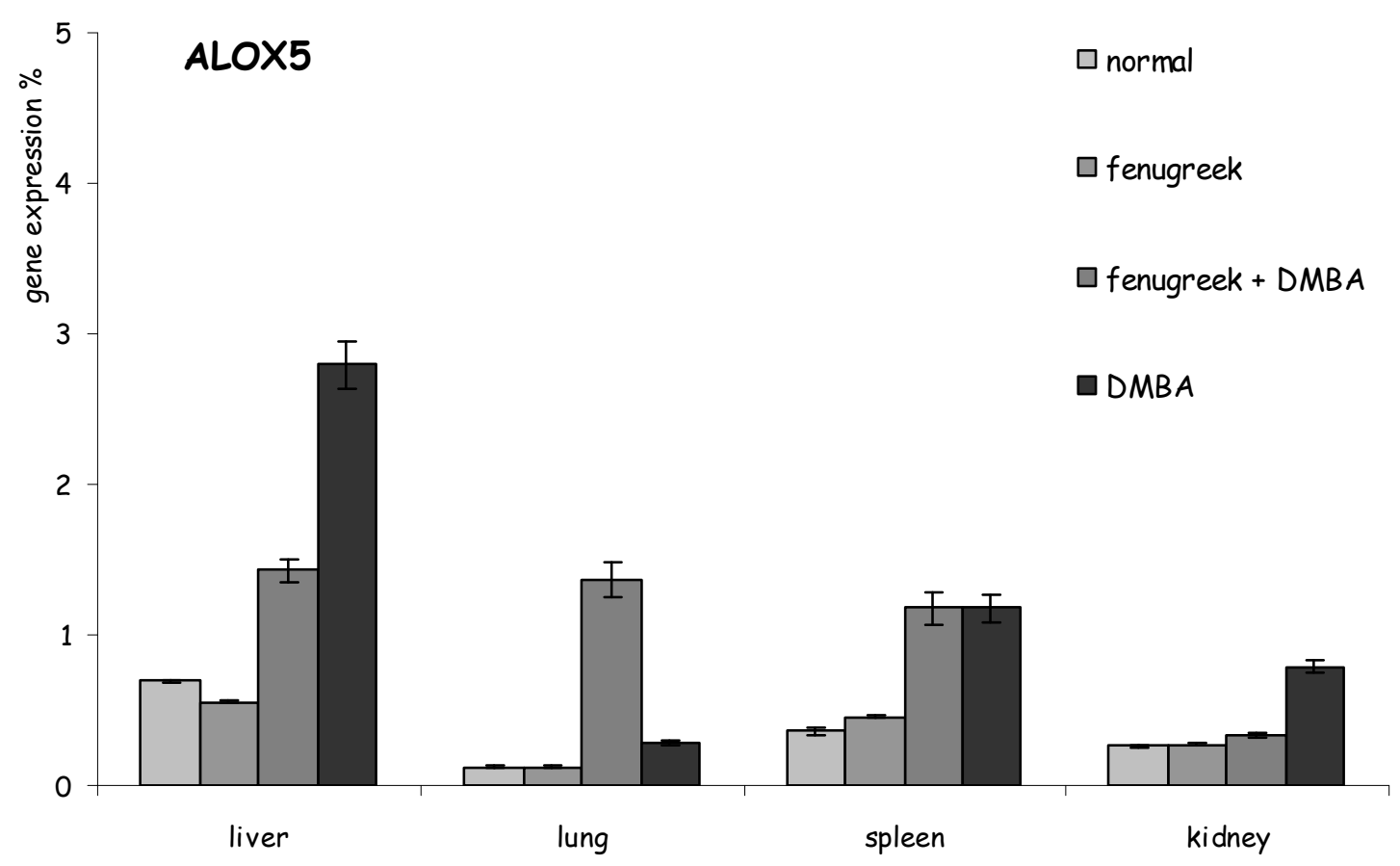

Figure 3.: The ALOX5 gene expression pattern and confidences interval of mRNA isolated from $\mathrm{AKR} / \mathrm{J}$ mice liver, lung, spleen and kidney tissues (the arbitrary unit is gene expression $\%$ of HPRT1 gene) 


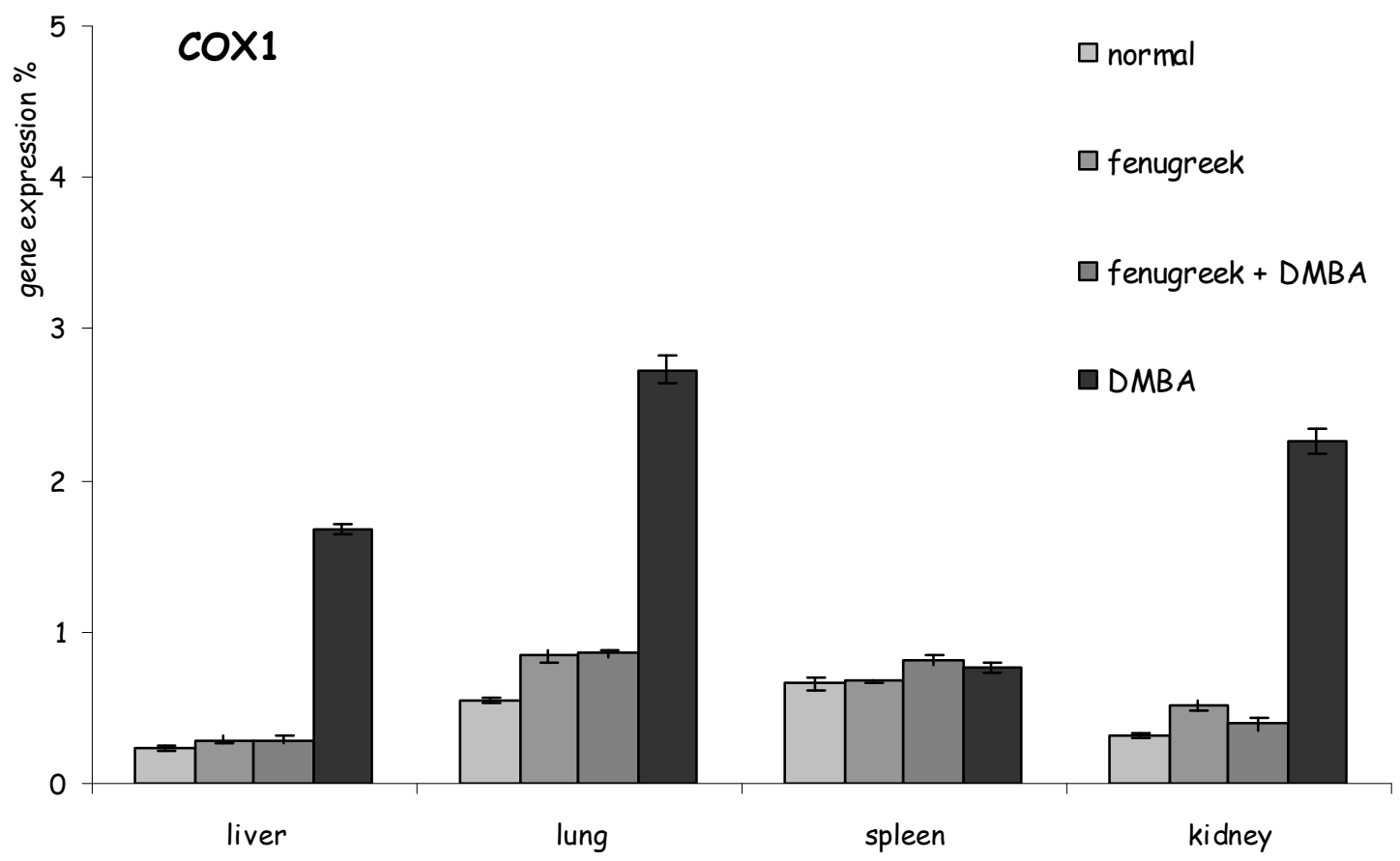

Figure 4.: The COX1 gene expression pattern and confidences interval of mRNA isolated from AKR/J mice liver, lung, spleen and kidney tissues (the arbitrary unit is gene expression $\%$ of HPRT1 gene) 


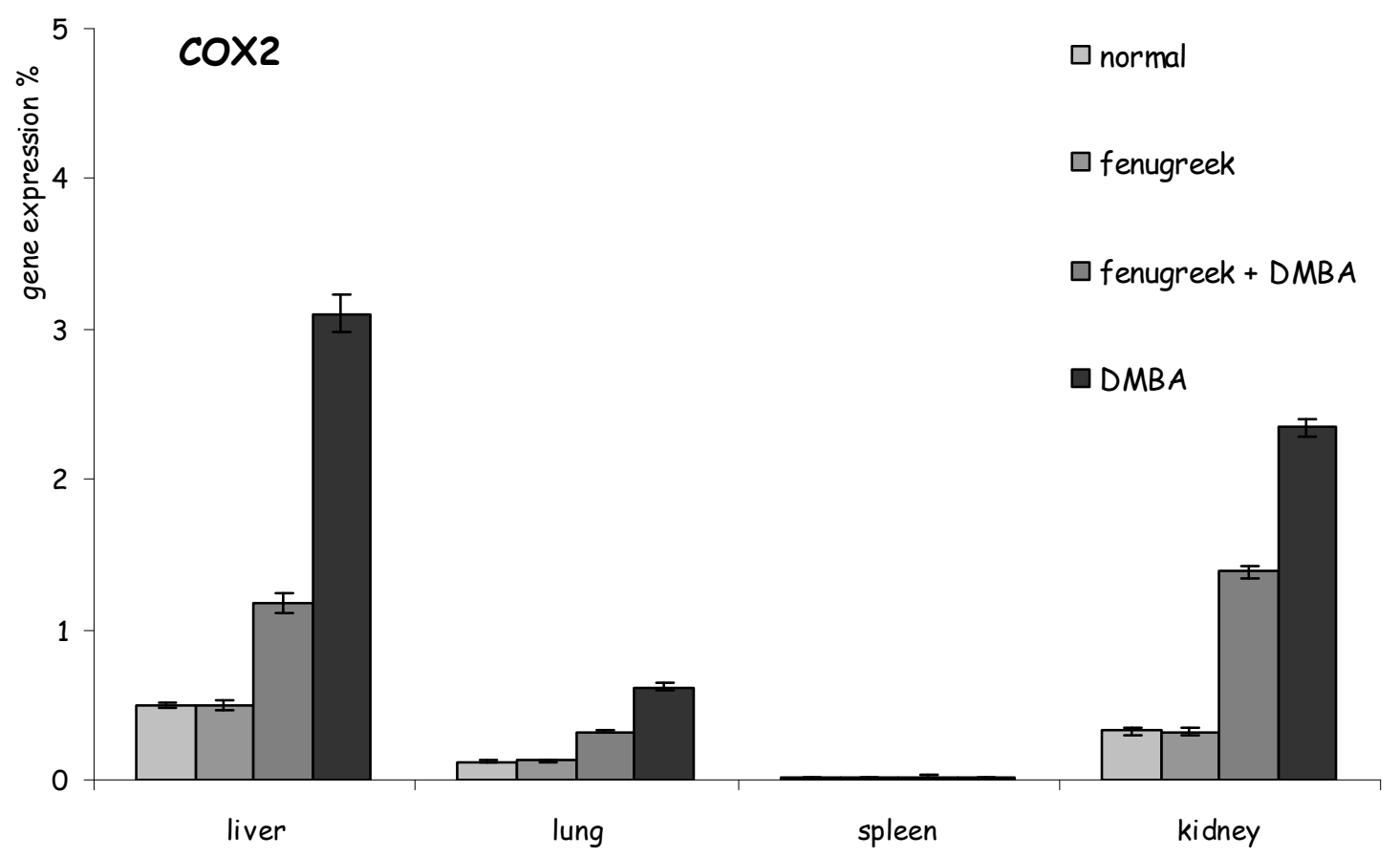

Figure 5.: The COX2 gene expression pattern and confidences interval of mRNA isolated from AKR/J mice liver, lung, spleen and kidney tissues (the arbitrary unit is gene expression $\%$ of HPRT1 gene) 